\title{
Integrating Telemedicine Services in Ophthalmology: Evaluating Patient Interest and Perceived Benefits
}

\author{
Eric J Shiuey' \\ Yehuda Fox ${ }^{2}$ \\ Adam Kurnick ${ }^{2}$ \\ Rony Rachmiel ${ }^{2,3}$ \\ Shimon Kurtz ${ }^{2,3, *}$ \\ Michael Waisbourd (iD) $2,3, *$ \\ 'Sidney Kimmel Medical College, Thomas \\ Jefferson University, Philadelphia, PA, USA; \\ ${ }^{2}$ Sackler Faculty of Medicine, Tel Aviv \\ University, Tel-Aviv, Israel; ${ }^{3}$ Department of \\ Ophthalmology, Tel Aviv Medical Center, \\ Affiliated to the Sackler Faculty of Medicine, \\ Tel Aviv University, Tel-Aviv, Israel \\ *These authors contributed equally to this \\ work
}

Correspondence: Michael Waisbourd Department of Ophthalmology, Tel Aviv Medical Center, Affiliated to the Sackler Faculty of Medicine,

Tel Aviv University, 6 Weizmann Street, Tel-Aviv, 64239, Israel

Tel +972-3-6974l65

Fax +972-3-697436I

Email michaelwa@tlvmc.gov.il
Purpose: The purpose of this study was to assess patient interest and willingness to pay (WTP) for teleophthalmology services, whose benefits include improved healthcare access and potential cost savings.

Patients and Methods: Cross-sectional study of 215 patients attending a single tertiary center to assess their interest in teleophthalmology. Comparisons between those interested and those not interested were conducted; logistic regression was used to evaluate the effect of price on interest.

Results: Two thirds (66.5\%) of patients were interested in teleophthalmology instead of inperson clinic visits. Those interested were significantly younger than uninterested patients ( $48.8 \pm 22.7$ vs $62.4 \pm 18.3$ years) and were more likely to miss work to attend clinic, own both a computer and smartphone, have experience with video conferencing, and use the internet frequently (all $\mathrm{P}<0.05$ ). Interested patients were also more likely to indicate time and cost savings, as well as improved follow-up testing, compared to uninterested patients (both $\mathrm{P}<0.001$ ). Overall, $70.4 \%$ of interested patients expressed WTP out-of-pocket for teleservices, especially at low ( $<\$ 14$ US dollars) and moderate-high $(>\$ 28)$ price points. Higher level of education was associated with WTP $(\mathrm{OR}=2.31,95 \%$ CI 1.05-5.06; $\mathrm{P}=0.037)$.

Conclusion: Most patients were interested in teleophthalmology services, especially if they were young, would otherwise miss work, and were familiar with electronics, video conferencing, and internet use. Most interested patients expressed WTP out-of-pocket. Targeting factors related to teleophthalmology interest may increase patient use and enhance communication, thereby improving healthcare access and follow-up.

Keywords: remote consultation, telemedicine, teleophthalmology, adherence to follow-up

\section{Introduction}

Limited patient access to medical care poses a population health challenge, especially during public health crises such as the 2019 coronavirus disease (COVID-19) pandemic. ${ }^{1,2}$ In-clinic examination allows ophthalmologists to closely examine microscopic ocular structures for pathology, but limits access to care for those who live far from an ophthalmology clinic. Furthermore, during the COVID-19 pandemic, social distancing requirements may make patients and providers hesitant to undergo and perform medical examinations in clinic rooms with limited space. Previous studies have demonstrated that patients who live further from urban medical centers are less likely to receive eye examinations, ${ }^{3}$ and in diseases such as glaucoma, more than $30 \%$ of patients do not return for recommended follow-up tests, ${ }^{4-6}$ preventing optimal management. Telemedicine employs video conferencing to deliver medical care and testing remotely using internet-connected devices. 
Potential benefits of telemedicine include improved access to care, patient monitoring, efficiency, resource savings, and follow-up. ${ }^{7-11}$

Multiple studies have described the benefits of telemedicine in ophthalmology (teleophthalmology). ${ }^{12-14}$ Advancements in digital fundus photography ${ }^{10}$ and intraocular pressure measurement without the need for anesthetic eyedrops, ${ }^{15}$ coupled with the ubiquity of mobile devices, hold significant potential to improve delivery of primary and specialized ophthalmic care, which in certain cases reduces the need for in-person visits to medical facilities. $^{2,16-21}$

The constantly increasing capabilities of internetconnected devices have made telemedicine increasingly feasible to implement in routine healthcare. Israel ranks second in the world in smartphone ownership, with $88 \%$ of the public owning smartphones. ${ }^{22}$ This widespread mobile device ownership presents a unique opportunity: by implementing a telemedicine system that focuses on patient-owned devices as opposed to specialized devices (ie ones provided by the healthcare network), the cost of implementing a telemedicine system may be greatly reduced. This study investigates patients' attitudes towards and willingness to pay for teleophthalmology services.

\section{Materials and Methods}

This cross-sectional study was approved by the Institutional Review Board (IRB 0089-17-TLV) at Tel Aviv Medical Center (Tel Aviv, Israel) and adhered to the tenets of the Declaration of Helsinki. This research was conducted at the Tel Aviv Medical Center Ophthalmology outpatient clinic prior to the COVID-19 pandemic. In the waiting room prior to their visit, patients provided written informed consent and were given an anonymous questionnaire by medical students to assess their interest in teleophthalmology. Patients did not receive a stipend for participating.

Telemedicine services were defined as audio-visual communication obtained directly from home with the doctor. Telemedicine visits could include answering questions, or actual virtual consultation. In some cases, a patient could send the ophthalmologist a photograph of an external finding (for example, hordeolum of the eyelid, hyperemia etc.) taken at home, while in other cases, the patient should obtain a fundus photograph or other ancillary diagnostic tests prior to the telemedicine visit, depending on the subspecialty and specific case.
Queried data included demographical data (eg level of education); eye diagnosis and associated number of visits and treatments; time, cost, and mode of transportation used to attend the clinic; estimated number of work hours lost due to travel to the clinic; and participants' use and familiarity with wireless technologies. Finally, the degree of interest in receiving ophthalmologic care remotely was assessed using Likert scales, with responses ranging from 1 ("not interested") to 5 ("high level of interest"). For analysis, responses 1 to 3 were grouped as "Not Interested" and responses 4 or 5 were recoded as "Interested" in receiving teleophthalmology services. Willingness to pay (WTP) for a teleophthalmology appointment was also assessed using local currency (Israeli New Shekel [INS]) and converted to United States Dollars (USD) for analysis, rounded up to the nearest dollar amount at the time of survey administration (50 NIS equaling \$14 USD at the time of analysis).

\section{Statistical Analysis}

Statistical analyses were carried out using IBM SPSS Statistics for Windows, version 25.0 (IBM Corp., Armonk, NY, USA). Differences between groups were conducted using the appropriate statistical tests (eg $\chi^{2}$, Student's t, and Mann-Whitney $U$-tests). Logistic regression was applied to identify the effect of price on the interest in telemedicine, adjusted for age, gender, and education level. Statistical significance level is reported at the two-sided 0.05 alpha level.

\section{Results}

A total of 215 patients were enrolled and responded to the survey. Patient demographics are shown in Table 1. The mean \pm standard deviation age was $53.3 \pm 22.3$ years, and $57 \%$ of participants were men. More than one-third $(35.2 \%)$ of patients were attending the retina service and $40.9 \%$ reported $\geq 2$ visits per year. Nearly three-quarters (74.8\%) had been diagnosed with their ocular condition $\geq 1$ year prior. In total, $143(66.5 \%)$ were interested in teleophthalmology instead of coming to the clinic.

The characteristics of patients Interested and Not Interested in teleophthalmology are shown in Table 2. The average age of patients interested in teleophthalmology was significantly younger than that of those not interested $(48.8 \pm 22.7$ years vs $62.4 \pm 18.3$ years, $\mathrm{P}<0.001)$. A total of $79(37 \%)$ respondents indicated that they had to miss work due to clinic visits, and those interested in teleophthalmology were more likely to report missing 
Table I Participant Demographics and Clinical Characteristics $(\mathrm{N}=215)$

\begin{tabular}{|l|l|}
\hline & $\mathbf{n}(\%)$ \\
\hline Mean \pm SD age & $53.3 \pm 22.3$ \\
\hline Gender & \\
Male & $123(57.2)$ \\
\hline Country of Birth & \\
Israel & $145(67.4)$ \\
Eastern Europe & $25(11.6)$ \\
Other & $18(8.4)$ \\
Western Europe & $14(6.5)$ \\
United States of America & $13(6.0)$ \\
\hline Education Level & \\
Up to secondary & $113(52.6)$ \\
Post-secondary & $102(47.4)$ \\
\hline Diagnosis/Clinic & \\
Retina & $75(35.2)$ \\
Glaucoma & $30(14.1)$ \\
Cataract & $24(11.3)$ \\
Other & $20(9.4)$ \\
Cornea & $12(5.6)$ \\
Neuro-ophthalmology & $7(3.3)$ \\
Uveitis & $3(1.4)$ \\
Pediatric & $1(0.5)$ \\
Not sure/Did not respond & $41(19.2)$ \\
\hline Frequency of ophthalmologic visits per year & $119(57.8)$ \\
I & $35(17.0)$ \\
2 & $88(27.4)$ \\
3 & $25(11.6)$ \\
I-5 & $43(20.0)$ \\
\hline Years since diagnosis & \\
\hline I & \\
\hline
\end{tabular}

Abbreviation: SD, standard deviation.

work due to the visit $(\mathrm{P}=0.023)$. Gender, country of origin, educational level, travel time, clinic waiting time, and burden on an accompanying individual were not significantly associated with interest in teleophthalmology. Those interested in teleophthalmology were more likely to own both a computer and smartphone $(\mathrm{P}=0.003)$, have previous experience with web-based conferencing services $(\mathrm{P}=0.005)$, use the internet frequently $(\mathrm{P}<0.001)$, and envision themselves using teleophthalmology $(\mathrm{P}<0.001)$.

Most responders arrived using a private car or motorcycle $(43.3 \%, \mathrm{n}=62)$, followed by public transportation (29.4\%, $\mathrm{n}=42)$, taxi $(13.3 \%, \mathrm{n}=19)$, and by walking/ bicycle $(14.0 \%, n=20)$ (Table 3$)$. Over half of participants had a travel time of $\geq 20$ minutes (20-60 minutes, $36.6 \%$, $\mathrm{n}=52 ;>60$ minutes, $19.7 \%, \mathrm{n}=28)$, while $43.7 \% \quad(\mathrm{n}=62)$ travelled for $<20$ minutes to arrive at clinic. Estimated travel cost for most individuals $(78.6 \%, \mathrm{n}=110)$ was $<$ $\$ 20$. Those Interested in teleophthalmology were more likely to indicate that they would save travel time and money using teleophthalmology (median score 5.0 vs 3.0, $\mathrm{P}<0.001)$ and indicated a greater likelihood of getting a routine follow-up test during an online meeting than those at the clinic (median score 4.0 vs 2.0, $\mathrm{P}<0.001$ ) compared to those Not Interested.

A majority $(70.4 \%, n=100)$ of interested respondents indicated WTP out-of-pocket (ie privately, without the participation of a health fund or co-pay) for teleophthalmology. Of those willing to pay $(n=118), 28 \%(n=33)$ were willing to pay $<\$ 14,31 \%(n=36)$ were willing to pay $\$ 14$ to $\$ 28$, and $42 \%(n=49)$ were willing to pay $>\$ 28$. Those willing to pay $<\$ 14$ and $>\$ 28$ USD were especially interested in teleophthalmology $(\mathrm{OR}=9.83$ and 8.10 , respectively, both $\mathrm{P}<0.001)$ compared to those refusing to pay. Those willing to pay between $\$ 14-\$ 28$ were 3.4 times as likely to be interested in teleophthalmology than those refusing to pay. Patients with a higher level of education were more likely to be willing to pay for teleophthalmology services $(\mathrm{OR}=2.31,95 \%$ confidence interval $1.05-$ 5.06; $\mathrm{P}=0.037$ ) (Table 4). Age, gender, and frequency of visits did not play a significant role in patients' WTP outof-pocket.

\section{Discussion}

Telemedicine saves time for patients and allows for more widespread and consistent access to ophthalmologists, ${ }^{7-11}$ which is especially important during public health crises, such as the COVID-19 pandemic with social distancing requirements in place. Our study found that two-thirds of 215 ophthalmology patients surveyed at the Tel Aviv Medical Center were interested in teleophthalmology in place of physically coming to the clinic. Although further studies of implementation and patient outcomes are necessary to assess the efficacy of virtual visits, we believe that our present results can be used to justify and construct pilot teleophthalmology programs.

Similar to other studies, we found that patients who do not own or regularly use internet-connected devices and older individuals are less likely to be interested in telemedicine. $^{23,24}$ We also found that patients who own or frequently use internet-connected devices, those who have prior experience with videoconferencing, and those 
Table 2 Factors Associated with Interest in Teleophthalmology

\begin{tabular}{|c|c|c|c|c|}
\hline & $\begin{array}{l}\text { Total } \\
(n=215)\end{array}$ & $\begin{array}{l}\text { Interested } \\
(n=143)\end{array}$ & $\begin{array}{l}\text { Not Interested } \\
(n=72)\end{array}$ & P-value \\
\hline Mean age [years, mean $\pm \mathrm{SD}]$ & $53.3 \pm 22.3$ & $48.8 \pm 22.7$ & $62.4 \pm 18.3$ & $<0.001$ \\
\hline \multicolumn{5}{|l|}{ Loss of work due to visit? [\% (n)] } \\
\hline Yes & $36.9 \%(79)$ & $42.3 \%(60)$ & $26.4 \%(19)$ & 0.023 \\
\hline No & $63.1 \%(135)$ & $57.7 \%(82)$ & $73.6(53)$ & \\
\hline Arrives to clinic with escort [\% (n)] & $37.9 \%(8 I)$ & $38.7 \%(55)$ & $36.1 \%(26)$ & 0.709 \\
\hline Escort loses work hours [\% (n)] & $44.2 \%(42)$ & $49.2 \%(32)$ & $33.3 \%(10)$ & 0.147 \\
\hline \multicolumn{5}{|l|}{ Ownership in household [\% (n)] } \\
\hline Computer & $9.2 \%(16)$ & $6.6 \%(8)$ & $15.4 \%(8)$ & 0.003 \\
\hline Smartphone & $14.5 \%(25)$ & $9.9 \%(12)$ & $25.0 \%(13)$ & \\
\hline Combination of both & $76.3 \%(132)$ & $83.5 \%(101)$ & $59.6 \%(31)$ & \\
\hline \multicolumn{5}{|l|}{ Previous Use of Skype or similar web conferencing service? [\% (n)] } \\
\hline Yes & $76.4 \%(162)$ & $82.3 \%(116)$ & $64.8 \%(46)$ & 0.005 \\
\hline No & $23.6 \%(50)$ & $17.7 \%(25)$ & $35.2 \%(25)$ & \\
\hline \multicolumn{5}{|l|}{ How often do you use the internet? [\% (n)] } \\
\hline Daily & $71.0 \%(152)$ & $81.0 \%(115)$ & $51.4 \%(37)$ & $<0.001$ \\
\hline Weekly, monthly, or yearly & $18.2 \%(39)$ & $14.1 \%(20)$ & $26.4 \%(19)$ & \\
\hline Never & $10.7 \%(23)$ & $4.9 \%(7)$ & $22.2 \%(16)$ & \\
\hline \multicolumn{5}{|l|}{$\begin{array}{l}\text { Do you see yourself using more web services for medical follow-up } \\
\text { and eyecare? }[\%(n)]\end{array}$} \\
\hline Yes & $53.3 \%(114)$ & $67.8 \%(97)$ & $23.9 \%(17)$ & $<0.001$ \\
\hline No & $17.3 \%(37)$ & $3.5 \%(5)$ & $45.1 \%(32)$ & \\
\hline Maybe & $29.4 \%(63)$ & $28.7 \%(4 I)$ & $31.0 \%(22)$ & \\
\hline \multicolumn{5}{|l|}{ Willingness to pay out of pocket for remote services $[\%(n)]^{a}$} \\
\hline Yes & $\mathrm{n} / \mathrm{a}$ & $70.4 \%(100)$ & $\mathrm{n} / \mathrm{a}$ & $\mathrm{n} / \mathrm{a}$ \\
\hline No & $\mathrm{n} / \mathrm{a}$ & $29.6 \%(42)$ & $\mathrm{n} / \mathrm{a}$ & \\
\hline
\end{tabular}

Note: ${ }^{a}$ Data presented only for patients interested in teleophthalmology.

Abbreviations: SD, standard deviation; n/a, not applicable.

who had to miss work to attend clinic were significantly more likely to express interest in teleophthalmology. Optimizing these aspects when administering a teleophthalmology program and targeting reservations in certain populations with educational resources would be integral to fluid implementation of telehealth services. ${ }^{25}$

Regardless of the potential for long-term cost-savings, startup expenses for teleophthalmology will likely be an obstacle to widespread implementation in healthcare systems ${ }^{26}$ though patients' willingness to pay out-ofpocket for such appointments might help to balance such expenses. For these reasons, we queried patients' willingness to pay out-of-pocket for telemedicine, finding reassuringly that the large majority of patents interested in teleophthalmology were willing to pay out-of-pocket. Interestingly, compared to those not willing to pay, we observed a greater interest in telemedicine among those willing to pay $<\$ 14$ and $>\$ 28$ USD, possibly suggesting that those with fewer or greater financial means value teleservices more than those willing to pay the moderate amount (\$14 to $28 \mathrm{USD}$ ). Of note, a full face-to-face visit to a hospital clinic costs approximately $80 \mathrm{USD}$, and the amounts mentioned in the survey for willingness to pay out of pocket were generally lower. Further research is necessary to tease out these pricing intricacies and optimal payment structures, eg sliding scale, fee-for-service, subscription- or insurance-based.

While telemedicine may improve patient access to care, it is encouraging that a large proportion of our study participants expressed interest in teleophthalmology. However, older patients were less likely to express interest, even though they may have the most to gain from teleservices 
Table 3 Factors Related to Transportation and Willingness to Pay Out-of-Pocket Among Those Interested in Teleophthalmology Services $(\mathrm{N}=$ I43)

\begin{tabular}{|c|c|c|c|}
\hline & \multicolumn{3}{|c|}{$\begin{array}{l}\text { Willingness to Pay Out-of- } \\
\text { Pocket for a Telemeeting, } \\
\text { N (\%) }\end{array}$} \\
\hline & Willing & Unwilling & Total \\
\hline \multicolumn{4}{|l|}{$\begin{array}{l}\text { Mode of transportation to } \\
\text { clinic }\end{array}$} \\
\hline Motorcycle/private car & $48(47.5)$ & $14(33.3)$ & $62(43.4)$ \\
\hline $\begin{array}{l}\text { Public transportation/special } \\
\text { service }\end{array}$ & $22(2 \mid .8)$ & $20(47.6)$ & $42(29.4)$ \\
\hline Taxi & 14 (13.9) & $5(11.9)$ & $19(13.3)$ \\
\hline Walk/bicycle & $17(16.8)$ & $3(7.1)$ & $20(14)$ \\
\hline \multicolumn{4}{|l|}{$\begin{array}{l}\text { Length of travel from home to } \\
\text { clinic }\end{array}$} \\
\hline$\leq 20$ minutes & $49(49)$ & $13(3 \mid)$ & $62(43.7)$ \\
\hline 20-59 minutes & $32(32)$ & $20(47.6)$ & $52(36.6)$ \\
\hline$\geq 60$ minutes & $19(19)$ & $9(21.4)$ & $28(19.7)$ \\
\hline \multicolumn{4}{|l|}{$\begin{array}{l}\text { Estimated cost of travel to } \\
\text { clinic (including parking), USD }\end{array}$} \\
\hline$\leq \$ 10$ & $60(60.6)$ & $22(53.7)$ & $82(58.6)$ \\
\hline$\$ 10-19$ & $18(18.2)$ & $10(24.4)$ & $28(20)$ \\
\hline$\$ 20-49$ & II (II.I) & $6(14.6)$ & $17(12.1)$ \\
\hline$\geq \$ 50$ & $10(10.1)$ & $3(7.3)$ & $13(9.3)$ \\
\hline
\end{tabular}

Abbreviation: USD, United States Dollars.

due to comorbid medical conditions limiting their ability to attend in-person clinic and exacerbating their ocular conditions, and are more likely to experience disabling ocular morbidity. Educational interventions may be necessary to increase adoption in older patients, especially in a future where telemedicine is increasingly pervasive due to pandemics like COVID-19 limiting in-person visits. For instance, interested patients indicated that they perceived a benefit in the form of increased follow-up testing following teleophthalmology visits; this benefit might be emphasized for reluctant patients. Further, our finding that those with additional education beyond secondary school are more willing to pay out-of-pocket for teleophthalmology suggests that a lack of knowledge may be a barrier to receiving telemedicine. An educational program clearly elucidating the benefits of virtual services, especially targeted towards older patients, might enhance interest in this demographic. Specific resources for older patients, including videoconferencing education, tips for optimizing communication when wearing masks, and investment into hospital-provided, userfriendly devices, may improve usage in this population as well.

Further investigation is necessary to evaluate how teleophthalmology should be most effectively implemented, especially during epidemics or pandemics. Study of the integration of teleophthalmology into existing electronic medical infrastructure and investigation into optimal delivery and reimbursement systems are needed, as well as the continued development of teleophthalmology technology itself. $^{27,28}$ With further improvements, telemedicine may greatly reduce disparities in healthcare access during times of crisis, provide expanded care to an aging population, and increase cost-effectiveness and efficiency of healthcare systems globally. Nevertheless, the COVID-19 pandemic showed that disparities in healthcare access were actually amplified in some cases, rather than reduced. This is because only those of high enough socio-economic status had robust broadband technology at home and sufficient technical savvy, which could adequately participate in these types of video visits; this has been termed the "digital divide". Therefore, it is important to distinguish the different requirements that this type of telemedicine has compared to others where the patient is not responsible for technology.

One limitation of our study is that it was performed at a large metropolitan medical center, thus the patient population may not be generalizable to other more suburban or rural populations for whom telemedicine would greatly benefit but who may not have wide access to requisite technology. Additionally, surveys were administered in

Table 4 Association of Patient Characteristics with Willingness to Pay Out-of-Pocket for Virtual Consultation

\begin{tabular}{|l|l|l|l|l|}
\hline Factor Associated with Willingness to Pay Out-of-Pocket & OR & \multicolumn{2}{l|}{ 95\% CI } & \multicolumn{2}{l|}{ U } \\
\cline { 3 - 5 } & & Lower & Upper \\
\hline Age & 0.996 & 0.978 & 1.014 & 0.657 \\
Gender (male vs female) & 1.589 & 0.752 & 3.356 & 0.225 \\
Education Level (academic vs non-academic) & 2.305 & 1.050 & 5.058 & 0.037 \\
Loss of work due to clinic visit (yes vs no) & 1.467 & 0.629 & 3.419 & 0.375 \\
\hline
\end{tabular}

Abbreviations: $\mathrm{OR}$, odds ratio; $\mathrm{Cl}$, confidence interval. 
English and Hebrew, potentially excluding a small number of otherwise eligible patients who could not communicate in either language. Further, we did not assess the association of visual function or diagnosis with answers to our questionnaire, which may have had effects on patients' answers. Lastly, as we did not study the implementation of a teleophthalmology program, we cannot comment on potential cost-savings or patient outcomes.

\section{Conclusion}

Most patients we surveyed were interested in using teleophthalmology services instead of attending clinic visits, especially if they were younger and their visits were associated with loss of work. Experience with electronics, video conferencing, and internet use were also associated with interest. The vast majority of interested patients were also willing to pay for such services. Targeting those factors related to interest in telemedicine may increase patient use of teleophthalmology, thus enhancing patientphysician communication and improving access to eye care, which is important in the context of the COVID-19 pandemic and social distancing requirements. Utilizing teleophthalmology may additionally contribute to earlier diagnosis of chronic conditions, thus allowing earlier treatment implementation with better patient follow-up and disease control.

\section{Acknowledgments}

Ms. Zmira Silman is thanked for her assistance with statistical analysis.

\section{Disclosure}

Professor Michael Waisbourd reports grants, personal fees from Novartis, outside the submitted work. The author reports no other conflicts of interest in this work.

\section{References}

1. Williams JM, Ehrlich PF, Prescott JE. Emergency medical care in rural America. Ann Emerg Med. 2001;38:323-327. doi:10.1067/ mem.2001.115217

2. Saleem SM, Pasquale LR, Sidoti PA, et al. Virtual ophthalmology: telemedicine in a COVID-19 era. Am $J$ Ophthalmol. 2020;216:237-242. doi:10.1016/j.ajo.2020.04.029

3. Chou CF, Zhang X, Crews JE, et al. Impact of geographic density of eye care professionals on eye care among adults with diabetes. Ophthalmic Epidemiol. 2012;19:340-349. doi:10.3109/092865 86.2012.722244

4. Fudemberg SJ, Lee B, Waisbourd M, et al. Factors contributing to nonadherence to follow-up appointments in a resident glaucoma clinic versus primary eye care clinic. Patient Prefer Adherence. 2016;10:19-25.
5. Hark LA, Johnson DM, Berardi G, et al. A randomized, controlled trial to test the effectiveness of a glaucoma patient navigator to improve appointment adherence. Patient Prefer Adherence. 2016;10:1739-1748. doi:10.2147/PPA.S108391

6. Pizzi LT, Tran J, Shafa A, et al. Effectiveness and cost of a personalized reminder intervention to improve adherence to glaucoma care. Appl Health Econ Health Policy. 2016;14:229-240. doi:10.1007/s40258-016-0231-8

7. Bar-Sela SM, Glovinsky Y. A feasibility study of an internet-based telemedicine system for consultation in an ophthalmic emergency room. J Telemed Telecare. 2007;13:119-124. doi:10.1258/1357633 07780677640

8. Horton MB, Silva PS, Cavallerano JD, et al. Operational components of telemedicine programs for diabetic retinopathy. Curr Diab Rep. 2016;16:128. doi:10.1007/s11892-016-0814-7

9. Kumar S, Tay-Kearney ML, Constable IJ, et al. Internet based ophthalmology service: impact assessment. $\mathrm{Br} J$ Ophthalmol. 2005;89:1382-1383. doi:10.1136/bjo.2005.072579

10. Mansberger SL, Sheppler C, Barker G, et al. Long-term comparative effectiveness of telemedicine in providing diabetic retinopathy screening examinations: a randomized clinical trial. JAMA Ophthalmol. 2015;133:518-525. doi:10.1001/jamaophthalmol.2015.1

11. Rathi S, Tsui E, Mehta N, et al. The current state of teleophthalmology in the United States. Ophthalmology. 2017;124:1729-1734. doi:10.1016/j.ophtha.2017.05.026

12. Kennedy C, Bowman R, Fariza N, et al. Audit of web-based telemedicine in ophthalmology. J Telemed Telecare. 2006;12:88-91. doi:10.1258/135763306776084356

13. Labiris G, Panagiotopoulou EK, Kozobolis VP. A systematic review of teleophthalmological studies in Europe. Int $J$ Ophthalmol. 2018;11:314-325.

14. Chasan JE, Delaune B, Maa AY, et al. Effect of a teleretinal screening program on eye care use and resources. JAMA Ophthalmol. 2014;132:1045-1051. doi:10.1001/jamaophthalmol.2014.1051

15. Gao F, Liu X, Zhao Q, et al. Comparison of the iCare rebound tonometer and the Goldmann applanation tonometer. Exp Ther Med. 2017;13:1912-1916. doi:10.3892/etm.2017.4164

16. Boucher MC, Nguyen QT, Angioi K. Mass community screening for diabetic retinopathy using a nonmydriatic camera with telemedicine. Can J Ophthalmol. 2005;40:734-742. doi:10.1016/S0008-4182(05)80091-2

17. Cavallerano AA, Cavallerano JD, Katalinic P, et al. A telemedicine program for diabetic retinopathy in a veterans affairs medical centerthe Joslin vision network eye health care model. Am J Ophthalmol. 2005;139:597-604. doi:10.1016/j.ajo.2004.10.064

18. Fierson WM, Capone A Jr. American Academy of Pediatrics Section on $\mathrm{O}$; Telemedicine for evaluation of retinopathy of prematurity. Pediatrics. 135;2015:e238-254. doi:10.1542/peds.2014-0978

19. Gomez-Ulla F, Fernandez MI, Gonzalez F, et al. Digital retinal images and teleophthalmology for detecting and grading diabetic retinopathy. Diabetes Care. 2002;25:1384-1389. doi:10.2337/ diacare.25.8.1384

20. Quinn GE, Ying GS, Daniel E, et al. Validity of a telemedicine system for the evaluation of acute-phase retinopathy of prematurity. JAMA Ophthalmol. 2014;132:1178-1184. doi:10.1001/ jamaophthalmol.2014.1604

21. Williamson TH, Keating D. Telemedicine and computers in diabetic retinopathy screening. Br J Ophthalmol. 1998;82:5-6. doi:10.1136/ bjo.82.1.5

22. Silver L. Smartphone ownership is growing rapidly around the world, but not always equally. Pew research center's global attitudes project; 2019. Available from: https://www.pewresearch.org/global/2019/02/ 05/smartphone-ownership-is-growing-rapidly-around-The-world-butnot-always-equally/. Accessed February 14, 2020.

23. Foster A, Horspool KA, Edwards L, et al. Who does not participate in telehealth trials and why? A cross-sectional survey. Trials. 2015;16:258. doi:10.1186/s13063-015-0773-3 
24. Mancini J, Nogues C, Adenis C, et al. Patients' characteristics and rate of internet use to obtain cancer information. J Public Health. 2006;28:235-237. doi:10.1093/pubmed/fd1019

25. Areaux RG Jr, de Alba Campomanes AG, Indaram M, et al. Your eye doctor will virtually see you now: synchronous patient-to-provider virtual visits in pediatric tele-ophthalmology. $J$ AAPOS. 2020;24:197-203. doi:10.1016/j.jaapos.2020.06.004

26. Kumar S, Tay-Kearney ML, Chaves F, et al. Remote ophthalmology services: cost comparison of telemedicine and alternative service delivery options. J Telemed Telecare. 2006;12:19-22. doi:10.1258/ 135763306775321399
27. de Bont A, Bal R. Telemedicine in interdisciplinary work practices: on an IT system that met the criteria for success set out by its sponsors, yet failed to become part of every-day clinical routines. BMC Med Inform Decis Mak. 2008;8:47. doi:10.1186/1472-6947$8-47$

28. Bowe T, Hunter DG, Mantagos IS, et al. Virtual visits in ophthalmology: timely advice for implementation during the COVID-19 public health crisis. Telemed J E Health. 2020;26:1113-1117. doi:10.1089/ tmj.2020.0121

\section{Publish your work in this journal}

Patient Preference and Adherence is an international, peer-reviewed, open access journal that focusing on the growing importance of patient preference and adherence throughout the therapeutic continuum. Patient satisfaction, acceptability, quality of life, compliance, persistence and their role in developing new therapeutic modalities and compounds to optimize clinical outcomes for existing disease states are major areas of interest for the journal. This journal has been accepted for indexing on PubMed Central. The manuscript management system is completely online and includes a very quick and fair peer-review system, which is all easy to use. Visit http:// www.dovepress.com/testimonials.php to read real quotes from published authors. 